\title{
EDUCAÇÃO SEXUAL PARA PESSOAS COM DEFICIÊNCIA FÍSICA
}

\author{
Ana Cláudia Bortolozzi MAIA ${ }^{1}$ \\ Marcelo Gonçalves RODRIGUES ${ }^{2}$ \\ Fernanda Piqueira GOMES ${ }^{3}$ \\ Priscila Foger MARQUES ${ }^{4}$
}

RESUMO: Pessoas com deficiência física são seres sexuados que necessitam receber esclarecimentos e educação sexual. Este trabalho descreve um programa de intervenção em educação sexual para pessoas com deficiência física que teve por objetivos: a) transmitir uma noção ampla e emancipatória de sexualidade, b) esclarecer e informar sobre a educação e repressão sexual, c) refletir sobre as mudanças na imagem corporal e autoestima da pessoa com deficiência física e suas implicações na sexualidade e d) discutir sobre a crença social de que a deficiência é impeditiva para a sexualidade. $O$ programa foi realizado em dez encontros semanais de duas horas de duração e utilizouse de recursos pedagógicos como dinâmicas grupais, vídeos e imagens. Os jovens participaram ativamente, discutindo e refletindo sobre as questões sociais da sexualidade. Conclui-se que a população estigmatizada pela deficiência carece de esclarecimentos e reflexões sobre a construção social da sexualidade e da deficiência e que oportunidades de reflexões grupais em processos de educação sexual para essa população são fundamentais na sociedade inclusiva.

PALAVRAS-CHAVE: Educação sexual. Sexualidade. Deficiência física.

\footnotetext{
${ }^{1}$ UNESP - Universidade Estadual Paulista. Faculdade de Ciências - Departamento de Psicologia. Grupo de Estudos e Pesquisa Sexualidade, Educação e Cultura - GEPESEC. Bauru - SP - Brasil. 17033-360 aclaudia@fc.unesp.br

${ }^{2}$ UNESP - Universidade Estadual Paulista. Faculdade de Ciências - Departamento de Psicologia. Grupo de Estudos e Pesquisa Sexualidade, Educação e Cultura - GEPESEC. Bauru - SP - Brasil. 17033-360 marcelo_gonc@yahoo.com.br

${ }^{3}$ UNESP - Universidade Estadual Paulista. Faculdade de Ciências - Departamento de Psicologia. Grupo de Estudos e Pesquisa Sexualidade, Educação e Cultura - GEPESEC. Bauru - SP - Brasil. 17033-360 pgomes.fernanda@gmail.com

${ }^{4}$ UNESP - Universidade Estadual Paulista. Faculdade de Ciências - Departamento de Psicologia. Grupo de Estudos e Pesquisa Sexualidade, Educação e Cultura - GEPESEC. Bauru - SP - Brasil. 17033-360 priscila.foger@yahoo.com.br
}

\section{Introdução}

Estudos sobre a sexualidade de pessoas com deficiência apontam diversas crenças que contribuem para uma percepção de uma sexualidade desvantajosa para essa população. No entanto, os possíveis problemas na expressão da sexualidade, quando há uma deficiência, refletem questões sociais e nem sempre as orgânicas (MAIA, 2011). 
A sexualidade configura-se em um fenômeno social e humano que é caracterizado por atitudes, crenças, valores e regras a partir de configurações culturais e históricas (FOUCAULT, 1988). Os sentimentos e práticas sexuais reproduzem julgamentos sociais que balizam o que seria normal ou patológico, adequado ou inadequado, esperado ou desviante (ANDERSON, 2000; BLACKBURN, 2002; MAIA, 2011).

Nesse cenário a sexualidade "normal" inclui a funcionalidade, que potencialmente existe em todo ser humano, da chamada resposta sexual: desejo, excitação e orgasmo. Problemas comuns relacionados a essas fases da resposta sexual para pessoas com deficiência podem ser generalizados a uma sexualidade que se considera aqui, a expressão ampla de sensações eróticas e afetivas (MAIA, 2010). Pessoas sem deficiência podem igualmente ter problemas na expressão de sua sexualidade, assim como o inverso. Tomar essa relação como algo inevitável, é fruto de um preconceito (ANDERSON, 2000; BAER, 2003; KAUFMAN; SILVERBERG; ODETTE, 2003; MAIA, 2011; MAIA; RIBEIRO, 2010).

$\mathrm{O}$ conceito de sexualidade prioritariamente restrito às questões genitais e reprodutivas é imposto nos discursos diversos que atinge a todos. Para muitas pessoas acreditar que toda a sexualidade se resume ao sexo dificulta a compreensão de que a satisfação erótica e afetiva pode ocorrer independentemente das práticas sexuais. Além disso, padrões definidores de normalidade significam também noções sobre o corpo, a beleza física e a conjugalidade. Essas condições do corpo belo e saudável, da beleza relacionada à estética magra e a necessidade de casamento e reprodução são colocadas como atributos desejáveis à felicidade e no caso das pessoas estigmatizadas pela deficiência, a necessidade de corresponder a esses padrões pode ser algo que prejudica a inclusão social (PINEL, 1999; SALIMENE, 1995; WEREBE, 1984).

Todas as pessoas, independentemente de terem ou não uma deficiência, são seres sexuados. O que ocorre, muitas vezes, quando uma pessoa tem uma deficiência, é que as limitações costumam ser generalizadas para a vida sexual e amorosa e é comum a concepção de uma sexualidade atípica ou infeliz para essas pessoas (BLACBURN, 2002; KAUFMAN; SILVERBERG; ODETTE, 2003; PINEL, 1999; MAIA, 2011). Muitas afirmações e "mitos" sobre a sexualidade da pessoa com deficiência são comuns entre as pessoas, inclusive entre as pessoas com deficiência e seus familiares (SORRENTINO, 1990) que, acreditando nessas limitações impostas pela sociedade, introjetam sentimentos de inadequação (MAIA; RIBEIRO, 2010). 
Na sociedade inclusiva, o direito à expressão sexual, à vida sexual e reprodutiva e ao esclarecimento sobre sexualidade deve ser algo a ser alcançado em vários níveis. Diante desse argumento, este trabalho descreve uma proposta de educação sexual intencional para pessoas com deficiência física.

\section{Descrição da intervenção}

O programa foi desenvolvido como atividade proposta de estágio em Educação Sexual na Universidade Estadual Paulista “Júlio de Mesquita Filho" UNESP, no curso de Psicologia da Faculdade de Ciências, campus Bauru, no ano de 2012. O programa de intervenção teve como ponto de deslindamento a promoção de discussões sobre sexualidade para grupos de pessoas com deficiência física. A importância dessa intervenção, de maneira geral, foi a de se refletir sobre a concepção de sexualidade adotada pelo público alvo, no caso, as pessoas com deficiência.

Dessa forma, o objetivo geral foi problematizar essa temática junto a essa população, bem como as pessoas de seu convívio: cônjuges, familiares, amigos, etc. Portanto, o programa de Educação Sexual destinado às pessoas com deficiência, teve por devir inaugural a transmissão de uma compreensão alongada da sexualidade com as mediações inerentes à sociedade e à história do sujeito e desmistificar e esclarecer, acima de tudo, que a obtenção de prazer não se restringe exclusivamente ao coito genital.

Este programa de intervenção teve por objetivos específicos:

$\checkmark$ Transmitir uma noção ampla e emancipatória de sexualidade;

$\checkmark$ Esclarecer e informar sobre a repressão sexual como produto da educação comum que recebemos;

$\checkmark$ Refletir sobre as mudanças na imagem corporal e autoestima da pessoa com deficiência física e suas implicações na sexualidade;

$\checkmark$ Problematizar sobre a construção social e cultural de que a deficiência é limitadora da obtenção de prazer;

O programa foi desenvolvido em uma sala ampla no Centro de Psicologia Aplicada - CPA - UNESP, campus Bauru, no período de agosto a dezembro de 2012, com encontros semanais de duas horas de duração. Ao todo foram realizados 10 encontros.

O grupo contou com a participação de três pessoas com deficiência física dos quais dois com deficiência adquirida, sendo um homem de 24 anos por acidente 
automotor e uma mulher de 22 anos por acidente de bicicleta; o outro é homem de 23 anos com deficiência genética "Síndrome de Rothmund-Thompson". Todos os participantes eram vinculados à Associação de Pais e Amigos dos Excepcionais - APAE / Bauru.

Os conteúdos e temas abordados no programa foram:

- Integração do grupo; levantamentos de expectativas e apresentação da proposta;

- Concepção de sexualidade;

- Repressão sexual; vínculos afetivos; estereótipos e rótulos midiáticos;

- Autoestima antes e após a deficiência;

- Mitos na deficiência: as relações afetivas e sexuais de pessoas com deficiência;

- Resposta Sexual antes e depois da deficiência;

- Deficiência adquirida e questões familiares;

- Imagem corporal antes e após a deficiência.

Os recursos pedagógicos utilizados foram técnicas grupais; entrevistas; aulas expositivas dialogadas; recursos multimídia para apresentação de comerciais, filmes e documentários; representação da sexualidade humana por meio da confecção de cartazes com recorte e colagem de jornais e revistas.

\section{Resultados e discussão}

Cada encontro foi planejado previamente contendo tema principal, objetivos específicos, estratégias didáticas e avaliação processual. Brevemente apresentamos como se configurou cada temática:

\section{$\underline{1 . \text { Integração e apresentação da proposta }}$}

Nesse primeiro contato o objetivo foi o de promover a integração do grupo; levantar as expectativas em relação ao grupo; apresentar a proposta do grupo educativo. Para isso foram efetivadas as seguintes atividades: apresentação geral dos estagiários sobre o grupo e técnica grupal a entrevista do grupo que consiste basicamente em escolher alguém para entrevistar. O participante tem a possibilidade de fazer três perguntas, ou fazer uma e deixar que os demais façam as outras duas. Foi salientado que caso não se quisesse responder alguma pergunta, haveria a possibilidade de recusa. De modo geral, o entrevistador torna-se entrevistado e escolhe outra pessoa (alguém que ainda não tenha sido entrevistador) para lhe entrevistar. $\mathrm{O}$ jogo continua até que todos os membros do grupo tenham sido entrevistados. 


\section{Conceito amplo de sexualidade}

Esse tema trabalhado teve o propósito de analisar e discutir sobre o conceito de sexualidade e sua relação, na condição estigmatizada da deficiência, com o preconceito. Além disso, e principalmente, esclarecer dúvidas e informar ou acrescentar conhecimentos sobre a temática abordada. Foi feita uma breve introdução sobre o assunto, elencando diferenças entre sexo e sexualidade. Depois foi solicitado aos participantes que fizessem a confecção de cartazes capturando imagens que representassem a sexualidade humana. De fato, verificou-se a estereotipia em torno da sexualidade enquanto algo centrado nos órgãos genitais, a heteronormatividade bem como a valorização da virilidade.

\section{$\underline{\text { 3. Repressão sexual, vínculos afetivos, estereótipos e rótulos midiáticos }}$}

Nesse encontro o objetivo foi o de escancarar por meio da utilização de propagandas veiculadas diariamente sobre os rótulos e estereótipos corporais e o ideal de plenitude, o ideal de felicidade, para, além disso, mostrar os valores preconceituosos da sociedade de consumo. Dessa forma, os participantes foram informados que iria ser passado alguns trechos de comerciais variados e que a ideia era que eles observassem o que mais chamasse a atenção nestas propagandas. Foram veiculados um total de quatro propagandas: "close up epidemia do beijo”, "barbie tranças e mechas”, “comercial antigo All Day, cotidiano”, “desodorante Axe situação inusitada”. Esse exercício permitiu demonstrar aos participantes os rótulos, valores e imagem estereotipada bem como a perseguição pela felicidade que nos é vendida incessantemente. O ponto nodal da atividade foi verificar como essas figurações repercutiram em suas percepções e sentimentos em torno desses modelos ditatoriais. Eles solicitaram que se reprisassem as cenas para poderem compreender mais adequadamente a mensagem que em certa medida é criptografada quando se olha muito rapidamente. No caso, pôde-se destacar a heteronormatividade, o ideal de corpo jovem e atlético, a felicidade como norma de vida. Tais vídeos utilizados encontram-se disponíveis na internet. ${ }^{2}$

\section{Autoestima}

Para esse tema a proposta foi analisar os fatores que incidem positiva ou negativamente sobre a autoestima dos participantes deficientes bem como possibilitar abertura de espaço para que eles relatassem essas situações e quais seriam os

${ }^{2}$ https://www.youtube.com/watch?v=Sx-KWuladMg;

https://www.youtube.com/watch?v=vNUs_QLoYo8; https://www.youtube.com/watch?v=jnbZwFFRLWM; https://www.youtube.com/watch?v=ulMwVZlrs9U. 
determinados eventos que não afetariam suas autoestimas. Sendo assim, foi planejada a técnica das fichas, nessa atividade a proposta era saber a partir dos relatos deles quais momentos ou situações eles se viram afetados de forma positiva, negativa ou neutra. Para isso foram entregues fichas com símbolos significando o positivo (estrela), negativa (triângulo) e neutra (coração). Para cada situação narrada eles iriam classificar apontando a ficha e repassando aos estagiários para ser colado na cartolina. O objetivo foi verificar qual situação aparecia mais nas suas falas, se era positiva, negativa ou neutra. Em linhas gerais, emergiram as seguintes considerações da parte deles: tanto positiva como neutra se equalizaram, pois esses fatores da autoestima estavam no processo de reabilitação e participação em grupos de socialização esportiva ou de estudo; como parte negativa foram enfatizadas as partes sentimentais, mais especificamente, traições, desprezo e pena; dizendo de outro modo, sentimentos de dúvida sobre a verdadeira intenção dos parceiros: amor ou piedade.

5. Mitos na deficiência: as relações afetivas e sexuais de pessoas com deficiência

Nesse tema abordado o objetivo principal foi trabalhar as relações afetivas e sexuais das pessoas com deficiência, ou seja, demonstrar que a pessoa com deficiência é capaz de ter uma vida afetiva e sexual satisfatória. Para tanto, foram exibidas cenas específicas do filme "Intocáveis" para que se possibilitasse o entendimento ou identificação da parte deles com relação aos mitos que a sociedade ou as pessoas de forma geral apregoam com relação ao cuidado ou trato das pessoas com deficiência. $\mathrm{O}$ filme francês "Intocáveis" (2011), dirigido por Olivier Nakache e Eric Toledano, conta a história da amizade de Philippe - um homem que ficou tetraplégico por causa de um acidente ocorrido durante a condução de um parapente - e Driss - um jovem negro, que se torna cuidador de Philippe, embora não tenha buscado por isso. A afeição e confiança, que é estabelecida entre os dois homens, se desenvolve devido ao tratamento indiferençado que Driss dispensa a Philippe, isto é, lida da mesma forma que com qualquer pessoa - às vezes até por distração ou inexperiência. O jeito espontâneo de Driss cativou Philippe e ajudou a promover o desenvolvimento de sua autoestima. Por meio da interação com o rapaz, Philippe passou a expandir suas vivências: com o incentivo de Driss, o homem marca um encontro com a jovem com quem só se correspondia por cartas, desenvolvendo assim um relacionamento. De forma geral, eles foram pontuais e assertivos com relação à compreensão do filme, visto que souberam identificar os pontos centrais que gostaríamos de discutir e pensar, ou seja, captaram a 
ideia de que existem muitas crendices e excesso de cuidado da parte de terceiros, os retratando enquanto insuficientes, infantilizando-os e cerceando seus passos.

\section{$\underline{6 .}$ Resposta Sexual}

Para esse tema efetuou-se uma explicação expositiva sobre a resposta sexual humana trifásica: desejo, excitação e orgasmo. Assim foi feita a tentativa de solicitá-los que averiguassem o tema e falassem o que sabiam sobre, se já ouviram ou até mesmo se não faziam a mínima ideia do que se tratava. Houve por parte dos estagiários alguma dificuldade em conciliar os interesses de fala dos participantes, pois de certa forma $o$ diálogo por parte deles desembocou na questão da reposição hormonal e em um dos jovens o discurso em torno do acidente foi bem constante o que de certa forma inibiu as participações dos demais.

\section{Avaliação Final}

A avaliação final ocorreu no último encontro. Ele foi marcado pelo clima tranqüilo e descontraído. A proposta foi de não haver um assunto direcionado e deixalos livres para comentários gerais, direcionado aos encontros. Os participantes falaram sobre a importância que teve os encontros. Para eles foi preponderante entender a importância da privacidade, a compreensão de que o lazer é parte da recuperação. Outra questão trazida foi com relação ao namoro, pois um deles considerou que apenas estando $100 \%$ recuperado iria pensar num relacionamento. Questionado o que seria para ele estar $100 \%$ reabilitado, ele não soube precisar, mas concordou de certa forma que não há um momento propício para se determinar o início de um namoro. As conversas fluíram de forma agradável e em tom de despedida. Eles estavam emocionados com o fim dos encontros, ressaltaram diversas vezes a sensação de melhora e principalmente o reconhecimento de que os outros não se aproximam somente por pena ou compaixão.

Os resultados dos encontros evidenciaram questões gerais e específicas antevistas no planejamento dos conteúdos a serem abordados, como: queixas de ausência de tempo; isolamento; declínio da afetividade como frieza diante de si e dos familiares; perda da libido; sexualidade entendida na centralização da genitalidade; ira exacerbada diante de cuidados extremados que os mitificam enquanto crianças no estado de impotentes e sem juízo; amnésia; afirmação da heteronormatividade e virilidade; elevado sentimento de gratidão a divindades por estarem vivos e em fase de recuperação; sentimento de estar pecando quando sentiam desejo ou ficavam excitados; perda da referência da autoimagem; discurso de reelaboração do trauma. 


\section{Considerações finais}

A importância dos encontros foi evidente para esses jovens com deficiência. Ressalta-se sobre a necessidade deste programa ter continuidade, com maior tempo de duração e número de participantes, uma vez que o grupo configurou-se por poucas pessoas. Entretanto, embora possa parecer uma dificuldade, o grupo pequeno contribuiu para a confiança e o diálogo entre os membros do grupo que eram conhecidos entre si, oriundos da mesma instituição de reabilitação.

Entendemos que as condições sociais dominantes não configuram um alicerce suficientemente seguro à constituição de indivíduos que sejam diferenciados e dotados de autonomia. Vive-se na maioria do tempo de vida, espoliado da consciência de si mesmo e não se consegue compreender sua condição existencial ou manejar a realidade com vistas a evitar maiores prejuízos à autonomia. Esses prejuízos são gritantes na repressão sexual, nos mitos dilacerados e famigerados em torno do deficiente e na sua própria dificuldade em lidar com isso. Essa reflexão necessária na elaboração e realização das atividades do programa atingiu não somente as pessoas com deficiência participantes, mas também a equipe proponente.

Nesse sentido, um fato interessante que merece ser destacado é o paradoxo encontrado por nós no sentido de efetivar a proposta de desmistificar crendices do senso comum em torno da pessoa com deficiência em consonância às condições ignominiosas pelas quais eles têm que passar diariamente, pois no próprio desenvolvimento do programa lidamos com as mesmas dificuldades as quais existem em outros contextos, por exemplo, a acessibilidade interna do campus, a inviabilidade de adentrar circulares neste, além dos pontos de ônibus bem deslocados em relação ao local dos encontros e em consequência disso o modo invasivo e constrangedor que assumimos para os auxiliarem até o local do programa.

De fato, essas ocorrências infelizes possibilitaram que fosse trabalhado o inverso dessa lógica imposta, dialogar no sentido de tencionar o giro da percepção deles nessa configuração social contraditória e estratificada que de um lado efetua a pecha de que o individuo é o senhor de seu destino e que cabe unicamente a ele resolver seus dilemas, mas por outro, evidenciar que a mediação social e material é imprescindível, isto é, ressaltar a eles que impor ao deficiente a necessidade em participar de grupos de esclarecimento e socialização - sem que haja condições objetivas significativas no que 
tange a transporte, acessibilidade e infraestrutura - seria o mesmo que reproduzir e determinar o seu isolamento e exclusão.

Partindo da deficiência como um modelo social e dos limites para uma vida plena impostos pelas condições objetivas de vida, é que nos propusemos a abranger a discussão para as limitações no campo da sexualidade, cujas limitações impostas se consolidam na construção da subjetividade. Conclui-se que essa discussão permeada nos programas de educação sexual voltados para a população estigmatizada pela deficiência é fundamental e necessária e, no caso, possível e satisfatória.

\title{
SEXUAL EDUCATION FOR PEOPLE WITH DISABILITIES
}

\begin{abstract}
People with disabilities are sexual and they need clarifying and sexual education. This article describes an intervention program in sexual education for people with disabilities that have objective by: a) transmit a broad notion and emancipatory of sexuality, b) clarify and inform about education and sexual repression, c) reflect about changes in body image of the person's self-esteem with disability and implications in sexuality and d) discuss about the social belief that disability is an impediment to sexuality. The program was done in ten weekly meetings of two hours of duration and it is used of pedagogical resources such as group dynamics, videos and images. The young people participated actively, discussing and reflecting about social issues of sexuality. Concludes that the population stigmatized by disability lacks of clarifying and reflections about social construction of sexuality and of disability and that opportunities of group reflections on sexual education process for this population are fundamental in inclusive society.
\end{abstract}

KEYWORDS: Sexual Education. Sexuality. Disability.

\section{REFERÊNCIAS}

ANDERSON, O. H. Doing what comes naturally?: dispelling myths and fallacies about sexuality and people with developmental disabilities. Illinois: High Tide Press, 2000.

BAER, R. Is Fred dead?: a manual on sexuality for men with spinal cord injuries. Pennsylvania: Dorrance Publishing, 2003.

BLACKBURN, M. Sexuality \& disability. Oxford: Butterworth Heinemann, 2002.

FOUCAULT, M. A história da sexualidade I: a vontade de saber. 13.ed. Rio de Janeiro: Graal, 1988. 
KAUFMAN, M.; SILVERBERG, C.; ODETTE, F. The ultimate guide to sex and disability: for all of us who live with disabilities, chronic pain e illness. 2.ed.

California: Cleis Press, 2003.

MAIA, A. C. B. Inclusão e sexualidade na voz de pessoas com deficiência física. Curitiba: Juruá, 2011.

Conceito amplo de sexualidade no processo de educação sexual. Revista Psicopedagogia online. 2010. Disponível em:

<http://www.psicopedagogia.com.br/artigos/artigo.asp?entrID=1303>. Acesso em: 17 set. 2014.

MAIA, A. C. B.; RIBEIRO, P. R. M. Desfazendo mitos para minimizar o preconceito sobre a sexualidade de pessoas com deficiências. Revista Brasileira de Educação Especial, Marília, v.16, n.2, p.159-176, 2010.

PINEL, A. A restauração da Vênus de milo: dos mitos à realidade sexual da pessoa deficiente. In: RIBEIRO, M. (Org.). O prazer e o pensar: orientação sexual para educadores e profissionais de saúde. São Paulo: Gente, 1999. p.211-226.

SALIMENE, A. C. M. Sexo: caminho para a reabilitação. São Paulo: Cortez, 1995.

SORRENTINO, A. M. Handicap y rehabilitación: uma brújula sistêmica en el universo relacional delniño com deficiências físicas. Barcelona: Paidós, 1990.

WEREBE, M. J. G. Corpo e sexo: imagem corporal e identidade sexual. In: D'AVILA NETO, M. I. (Org.). A negação da deficiência: a instituição da diversidade. Rio de Janeiro: Achiamé/Socii, 1984. p.43-55. 